\title{
Nanotechnology Phenomena in the Light of the Solar Energy
}

\author{
Djamel Ghernaout ${ }^{1,2,{ }^{*}, \text { Abdulaziz Alghamdi }}{ }^{3}$, Mabrouk Touahmia $^{4}$, Mohamed Aichouni, \\ Noureddine Ait Messaoudene ${ }^{3}$
}

${ }^{1}$ Chemical Engineering Department, College of Engineering, University of Ha'il, Ha'il, Saudi Arabia

${ }^{2}$ Chemical Engineering Department, Faculty of Engineering, University of Blida, Blida, Algeria

${ }^{3}$ Mechanical Engineering Department, College of Engineering, University of Ha'il, Ha'il, Saudi Arabia

${ }^{4}$ Civil Engineering Department, College of Engineering, University of Ha'il, Ha'il, Saudi Arabia

${ }^{5}$ Industrial Engineering Department, College of Engineering, University of Ha'il, Ha'il, Saudi Arabia

\section{Email address:}

djamel_andalus@hotmail.com (D. Ghernaout)

${ }^{*}$ Corresponding author

\section{To cite this article:}

Djamel Ghernaout, Abdulaziz Alghamdi, Mabrouk Touahmia, Mohamed Aichouni, Noureddine Ait Messaoudene. Nanotechnology Phenomena in the Light of the Solar Energy. Journal of Energy, Environmental \& Chemical Engineering. Vol. 3, No. 1, 2018, pp. 1-8. doi: $10.11648 /$ j.jeece.20180301.11

Received: February 6, 2018; Accepted: February 24, 2018; Published: March 21, 2018

\begin{abstract}
Nowadays, nanotechnology is one of the most conducting research-based areas because it merges understanding from many disciplines such as Physics, Chemistry, Biology, Medicine, Engineering, and Environmental Sciences among others. There are no limits to the potential applications of nanotechnology. It is helping to considerably improve, even revolutionize, many technology and industry sectors. New nano- and bio-materials, and nano-devices, are produced and monitored through nanotechnology instruments and manners, which explore and transform the features, responses, and functions of living and non-living matter, at sizes below $100 \mathrm{~nm}$. This review focuses on nanotechnology, its definition and applications, and sunlight as a driving tool for developing nanotechnology. Sunlight as a free source of energy and clean agent for several physical and chemical reactions constitutes an increasing interest for both science and technology. Nanotechnology should focus on more using sunlight as a free energy source and an environmentally-friendly agent for its advancing for the human kind best future.
\end{abstract}

Keywords: Nanotechnology, Sunlight, Environment, Solar Energy, Photonics, Humankind Future

\section{Introduction}

Research and development into nanotechnology are at the speed of light expanding field, with many governments and industries worldwide spending billions of dollars trying to unravel the reasons why matter at the nanometer scale behaves differently from matter at the bulk scale and how to capitalize on these novel properties for the betterment of humanity $[1,2]$. There are several global challenges facing the humankind nowadays. They comprise finding sustainable renewable energy sources, decreasing pollution, supplying unpolluted potable water [3], diminishing the usage of pesticides and herbicides, enhancing agricultural outputs to feed an augmenting population, and predicted variations in world climate resulting from global warming. Nanotechnology and nanoscience have the capacity to provide solutions to several of these global challenges [1, 4-8].

This review focuses on nanotechnology, its definition and applications, and sunlight as a driving tool for advancing and developing nanotechnology. Sunlight as a free source of energy and clean agent for several physical and chemical reactions constitutes an increasing interest for both science and technology.

\section{Eating Sunlight for Energy}

The most important concept, the essential approach of all life, is to keep energy. Whatever you perform, whatever you want, whatever feels good for you, these are all 
psychological replies that illustrate you how to be more energy active [9]. Life desires energy, and subconsciously you'll always select the way of least resistance due to that. That is why high-calorie food tastes better, why whenever your beliefs are questioned you naturally refuse any arguments, and why people feel more depressed when there is no sunshine outside. However, what is the source of the human energy? How can more energy can be gained? How human consciousness can be raised and human intelligence can be increased? Nikola Tesla perfectly concluded the main, most fundamental source of human energy, and how to elevate human energy and evolve as a species [9]:

"First let us ask: Whence comes all the motive power? What is the spring that drives all? We see the ocean rise and fall, the rivers flow, the wind, rain, hail, and snow beat on our windows, the trains and steamers come and go; we hear the rattling noise of carriages, the voices from the street; we feel, smell, and taste; and we think of all this. And all this movement, from the surging of the mighty ocean, to that subtle movement concerned in our thought, has but one common cause. All this energy emanates from one single center, one single source, the sun. The sun is the spring that drives all. The sun maintains all human life and supplies all human energy."

Food is one of the most crucial elements of augmenting your mass. What is considered as food is just processed sunlight. Plants, with their photosynthesis [10], combine carbon, hydrogen and oxygen, and bind them through sunlight, forming the $\mathrm{CHO}$ molecule (fat) that are consumed through food and burn for energy. But the actual energy comes from freeing the photons of light between the chemical bond. That is what generates heat. That is what provides calories, which are stored photons. Sunlight is eaten for energy! [9].

Fruits, vegetables, meat; everything that is eaten has consumed the CHO (carbohydrate) molecules that the plants generated. The energy that is consumed through food is actually the very same energy - or sunlight $[11,12]$ - that the plants used to forge these elements together $[13,14]$. When meat is eaten, one is actually eating already consumed, unused $\mathrm{CHO}$ molecules (unused because $\mathrm{CHO}$ is only created through photosynthesis [10]). It is second hand $\mathrm{CHO}$ in a way [9].

\section{Photonics}

Photonics is the science of light. It is the technology of forming, controlling, and detecting light waves and photons, which are particles of light. The characteristics of the waves and photons may be employed to investigate the nature, cure diseases, and even to solve crimes. Scientists have been examining light for hundreds of years. The colors of the rainbow are only a little fraction of the entire light wave range, called the electromagnetic spectrum. Photonics studies a larger variety of wavelengths, from gamma rays to radio, comprising X-rays, UV and infrared light $[15,16]$.

It was only in the $17^{\text {th }}$ century that Sir Isaac Newton illustrated that white light is constituted of various colors of light. At the beginning of the $20^{\text {th }}$ century, Max Planck and later Albert Einstein suggested that light was a wave as well as a particle, which was a very controversial theory at the period. How may light be two totally various things at the same moment? Experimentation later confirmed this duality in the nature of light. The word Photonics appeared around 1960, when the laser was invented by Theodore Maiman [15].

\section{Energetic Nanoparticles Convert Sunlight into Electricity}

Electricity-generating solar cells are one of the most interesting choices for forming a long-term sustainable energy system; however, thus far solar cells have not been capable to rival economically with fossil fuels. Scientists are now focusing at how nanotechnology may participate in decreasing the cost [1, 17-20].

Solar cells are constructed of layers that absorb sunlight and transform it to electrical current. Thinner solar cells may generate both cheaper and more plentiful electricity than today's cells, if their capacity to absorb sunlight is optimized. One manner to improve the absorption of the solar harvesting material in a solar cell is to make use of nanoparticles of noble metal [17]. Hägglund [21] focused at how this may be performed.

The particles implied have special optical features attributed to the fact that their electrons oscillate back and forth together at the same rate as the frequency of the light, that is, the color of the light. The particles catch the light as tiny antennas and via the oscillations the energy is passed on as electricity. These oscillations, plasmons, are very forceful at certain so-called plasmon resonance frequencies, which in turn are affected by the form, size, and surroundings of the particles [17].

As Hägglund said [17]"What we have done is to make use of nanotechnology to produce the particles and we have therefore been able to determine the properties and see how they can enhance the absorption of light of different colors."

In the context of solar cells, the great challenge is to efficiently convert the energy that is absorbed in the electron oscillation to energy in the form of electricity [4, 17].

As Hägglund added [17] We show that it is precisely the oscillations of the particles that yield the energy, how it is transmitted to the material and becomes electricity. It might have turned out, for example, that the oscillations simply generated heat instead."

The performance of the best solar cells nowadays is already very elevated. The possibility of reaching even better solar cells therefore depends on employing less material and in decreasing production costs. With solar cells of particularly conceived nanoparticles of gold, which is what Hägglund has searched, a layer only a few nanometers thick is required for the particles to be able to absorb light in an efficient way [17]. 
Hägglund [21] investigated the influence of nanoparticles of noble metal on two various kinds of solar cells, which may be considered to show two opposites. In one kind of solar cell the light is absorbed in molecules on a surface, and in the other type deep inside the material (Figure 1). The experimental and theoretical results illustrate that the particles may help transmit the light's energy to useful electricity in many various fashions and that it is easy to ameliorate the absorption of solar cells both on the surface and deep inside via various mechanisms.

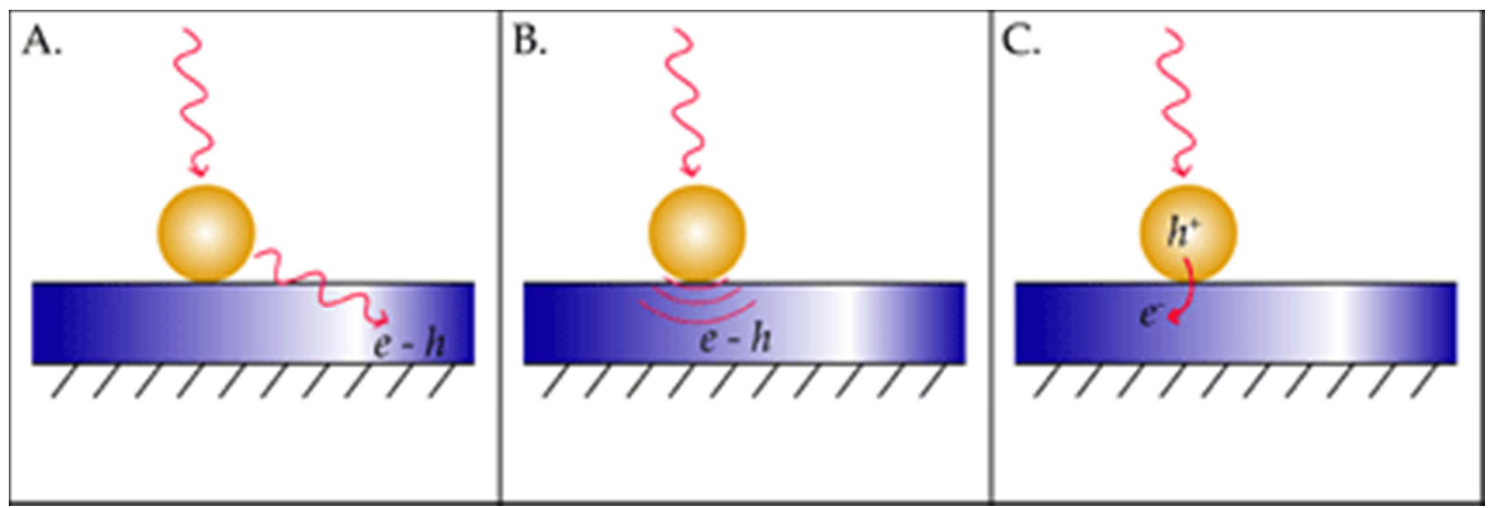

Figure 1. Light can be converted to electricity via plasmon resonances in nanoparticles, by: A: a far field effect which prolongs the optical path through the cell, B: a near field effect which locally enhance the energy conversion in the solar cell, or C: a creation of energy rich charge carriers which are transferred to the solar cell [21].

\section{Light Moves}

A system for the programmed assembly of light-gathering elements or chromophores is explained [10]. In natural systems, such as plants and photosynthetic bacteria, the spatial organization of densely packed chromophores is crucial for effective, directed energy transfer. Such biological systems order chromophores in accurate fashion on rigid scaffolds constituted of protein.

Substantially all life on earth depends directly or indirectly on photosynthesis. The organisms employing it expeditiously transfer the energy of sunlight from receptors, which collect photons from sunlight, to reaction centers where the energy may be used-an efficiency simply competing with the most performing man made solar cells $[4,10]$.

Attempts to comprehend natural light harvesting systems in plants and photosynthetic microbes date back at least a century. Even though the phenomena have been comprehended in broad outline, the details turn out to be complex and the challenges in generating synthetic analogues have been important $[4,10]$.

Efforts to understand natural light harvesting systems in plants and photosynthetic microbes date back at least a century. Although the phenomena have been understood in broad outline, the details turn out to be complex and the challenges in creating synthetic analogues have been significant $[4,10]$.

Plants perform photosynthesis by transforming photons of light striking their chromophores into another form of energy known as an exciton. An exciton is an energetic state of a molecule, or closely coupled group of molecules after they are excited by light absorption. Excitons are crucial in both natural photosynthesis and research attempts to duplicate the process, since they may transport energy from one molecule to another, energy that may finally be employed to power the motion of electrons $[4,10]$.

\section{Nanotechnology}

Nanotechnology is the science of comprehending and monitoring matter at very small dimensions spanning 1 to 100 nanometers (nm) [18, 22-24]. For comparison, a fingernail grows about $1 \mathrm{~nm}$ in a second (Figure 2). Matter like gases, liquids, and solids may show remarkable physical, chemical, and biological characteristics at the nanoscale, varying in significant manners from the same material in bulk. These improved characteristics comprise augmented strength, lighter weight, more monitoring of the light spectrum, and bigger chemical responsivity. Such processes arise both from quantum effects, which govern particle behavior and properties at the nanoscale [25], and from the bigger surface areas of nanomaterials. This augmented surface area per mass lets more of the material to enter into touch with neighboring materials. Several crucial chemical and electrical reactions happen hardly at surfaces and are responsive to surface form, texture, and chemical constitution. Furthermore, several nanoscale materials may mechanically put together into organized forms, allowing atom-by-atom conception of materials for particular motives. These elements render nanotechnology good for energy utilizations [18, 22, 26-29]. 


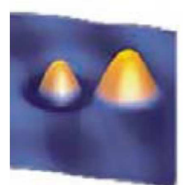

Gold atom

$\sim 0.1 \mathrm{~nm}$

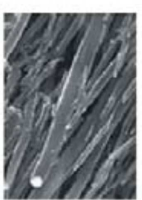

C nanotube $\sim 1 \mathrm{~nm}$

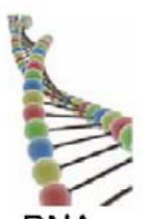

$\sim 3 \mathrm{~nm}$

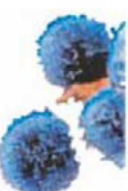

HIV virus

$\sim 100 \mathrm{~nm}$

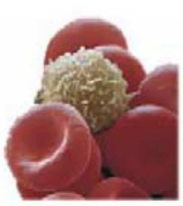

Blood cell $\sim 7 \mu \mathrm{m}$

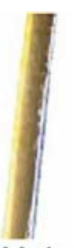

Hair

$\sim 100 \mu \mathrm{m}$

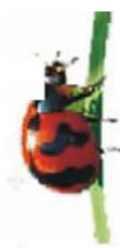

Insect

$\sim 10 \mathrm{~mm}$

$\begin{array}{lllllllll} & & & & & & & \\ \mathrm{nm} & 1 \mathrm{~nm} & 10 \mathrm{~nm} & 100 \mathrm{~nm} & 1 \mu \mathrm{m} & 10 \mu \mathrm{m} & 100 \mu \mathrm{m} & 1 \mathrm{~mm} & 10 \mathrm{~mm}\end{array}$

Figure 2. Length scale and some examples related [24].

Table $1[18,22,30-33]$ lists some frequent usages of nanotechnology.

Table 1. Usual utilizations of nanotechnology [18, 22, 30-33].

\begin{tabular}{|c|c|}
\hline $\begin{array}{l}\text { Utilization of } \\
\text { nanotechnology }\end{array}$ & Description \\
\hline $\begin{array}{l}\text { Energy, fuels and } \\
\text { environment }\end{array}$ & $\begin{array}{l}\text { With their new features coming to light from augmented surface area and quantum impacts, nanomaterials are employed in } \\
\text { batteries, photovoltaics, fuel cells, superconductors, solid-state lighting, lubricants, and the rmoelectrics. Moreover, they have a } \\
\text { crucial contribution in catalysts, which both accelerate natural chemical reactions and allow those not easily taking place in nature. } \\
\text { They transform raw materials, like crude oil, into products, such as gasoline or plastics, and let transform hazardous wastes into } \\
\text { benign mixtures before they go into the nature. }\end{array}$ \\
\hline Water & $\begin{array}{l}\text { Access to potable water has become an issue through the world. Nanomaterials may be a minute solution to this big issue. } \\
\text { Nanomaterials may strip water of hazardous metals and organic molecules. As an illustration, scientists have found that nanometer- } \\
\text { scale specks of rust are magnetic, which may assistin eliminatingtoxic chemicals from water. Other researchers are improving } \\
\text { nanostructured filters that may eliminate virus cells from water. Engineers are as well testing with employing nanotechnology to } \\
\text { safely, affordably, and efficiently turn saltwater into freshwater, a process named desalination. In one test, nano-sized electrodes are } \\
\text { being employed to decrease the cost and energy needs of eliminating salts from water [18, 32]. }\end{array}$ \\
\hline & Nanoparticulate preparations of classical medicaments are being employed to cure cancer and infectious diseases [30, 33]. \\
\hline Medicine & $\begin{array}{l}\text { Additional medical uses founded on nanotechnology comprise agents and therapeutics that target tumor cells and arterial plaques, } \\
\text { and novel diagnostic implements able of discovering extremely small amounts of significant disease biomarkers (Figure } 3 \text { ). }\end{array}$ \\
\hline Consumer products & $\begin{array}{l}\text { The utilization of nanomaterials in cosmetics, sunscreens, food products, and clothing is increasing in size. In sunblocks, the small } \\
\text { size of these particles allows high-power defense without rendering skin appear pasty white, and antimicrobial features in food } \\
\text { packaging remain food fresher and safer for longer periods. }\end{array}$ \\
\hline
\end{tabular}

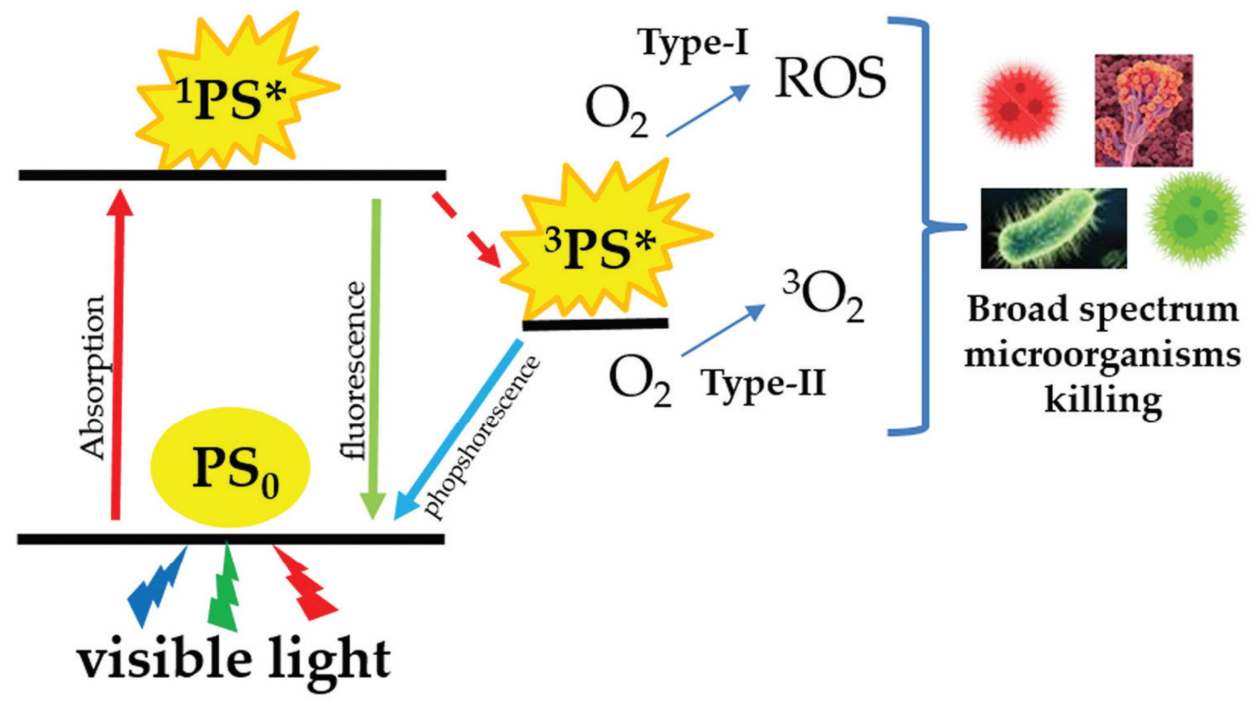

Figure 3. Schematic illustration of photodynamic action [31].

Table 2 lists a selection of naturally occurring things and man-made structures with their respective scale sizes to provide aglobal perspective of where the nanometer scale is compared to the macroscopic world [1]. 
Table 2. Comparative size scales between man-made, natural objects and some physical properties [1].

\begin{tabular}{llll}
\hline & & Examples & \\
\hline Power of Ten & Prefix, Symbol & Natural Things & Man-made Objects \\
\hline $10^{6}$ & mega, $\mathrm{M}$ & Radius of Earth $=\sim 6.366 \mathrm{Mm}$ & - \\
$10^{3}$ & kilo, $\mathrm{k}$ & Height of Mount Everest $=8.848 \mathrm{~km}$ & Span of the Golden Gate Bridge (distance between towers) $=1.280 \mathrm{~km}$ \\
$10^{2}$ & hecto, $\mathrm{h}$ & Speed of sound in 1 second $=\sim 343 \mathrm{~m}$ & Height of the Great Pyramid of Giza $=138.8 \mathrm{~m}$ \\
10 & deca, da & Height of Niagara & Height of the Leaning \\
$10^{-2}$ & centi, $\mathrm{c}$ & Falls $=52 \mathrm{~m}$ & Tower of Pisa $=55 \mathrm{~m}$ \\
$10^{-3}$ & milli, $\mathrm{m}$ & Length of a very largemosquito $=\sim 1.5 \mathrm{~cm}$ & Minimum diameter of a golf ball $=\sim 4.3 \mathrm{~cm}$ \\
$10^{-6}$ & micro, $\mu$ & Size of red blood cell $=\sim 7-8 \mu \mathrm{m}$ & Diameter of a pinhead $=\sim 1-2 \mathrm{~mm}$ \\
$10^{-9}$ & nano, $\mathrm{n}$ & DNA diameter $=2.5 \mathrm{~nm}$ & Microelectromechanical $(\mathrm{MEMS}$ ) device width $=\sim 10-100 \mu \mathrm{m}$ \\
$10^{-12}$ & pico, $\mathrm{p}$ & Carbon-carbon bondlength $=154 \mathrm{pm}$ & Carbon bucky ball diameter $=\sim 1 \mathrm{~nm}$ \\
\hline
\end{tabular}

\section{Mie Theory}

German physicist Gustav Mie participated in nanotechnology with his theory of light scattering by particles. His theory explains that light scatters from particles more efficiently at short wavelengths than at long wavelengths [34].

As an illustration, the sky is seen as being blue; this is due to the fact that the molecules in the air (which are tiny particles) scatter light from the sun more efficiently for blue light than for yellow or red, as blue light has the shorter wavelength (Figure 4). When the sun sets, the sunlight travels through the atmosphere over a longer distance than when it is overhead. The most significant scattering in this situation arises from dust particles. These particles still scatter light more effectively for blue colors, so the light that is not scattered is a mixture of red and yellow. This generates the characteristic red color of the setting sun [34].

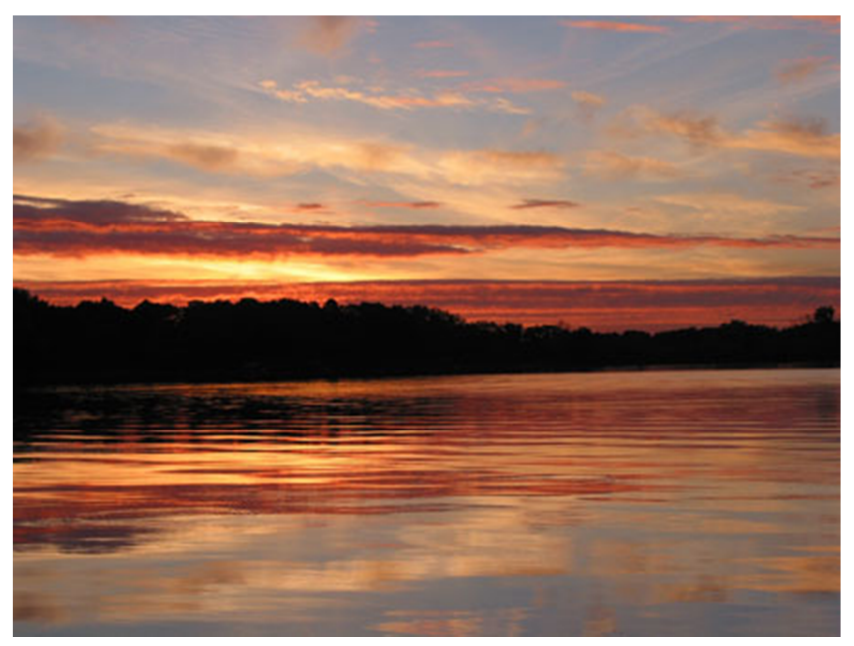

Figure 4. The Mie theory of light scattering interprets how various sized particles form the colors seen in the sky [34].

Mie theory assisted researchers to understand that the size of particles influences the colors seen. Mie went on to establish a manner to compute the size of particles by determining the light scatter. For nanoparticles and larger particles, this theory needs a great number of calculations; consequently, it was scarcely employed until about 20 years ago when supercomputers began to be at hand. Now, Mie theory (also others established more recently) assists scientists in predicting and calculating the size of nanoparticles [34].

\section{Sunlight's Nature and Composition}

Sun is the most important fountainhead of energy on the Earth [35]. Life exists on the Earth thanks to electromagnetic radiations, and in the absence of the Sun the life on Earth would not remain. The Earth releases an identical quantity of energy as it collects from the universe; consequently, there is heat stability on the Earth. The Sun streams an enormous amount of electromagnetic energy on it and all things on the Sun are the birthplace of these radiations. The Sun discharges through a large area of electromagnetic radiations (Figure 5). The fallen solar energy, mostly, is in the visible portion of the solar spectrum, during the time that the fundamental portion of the radiation is situated in the infrared area [35].

In eight minutes the radiation sent out from the Sun arrives to the Earth. The ray which illuminates the surface of the Earth is the visible light, as well as called white light, which is the unceasing blend of colors. This light when passed over the prism scatters into a range of seven colors. The energetic portion of the spectrum is the ultraviolet radiation, which is unnoticeable possessing shorter wavelengths in comparison with white light. Those of ultraviolet radiations possessing very shorter wavelengths are sieved in the outer atmosphere by the ozone layer [35].

Thermal radiations are the invisible infrared radiations possessing longer wavelengths in comparison with those of white light. Generally, the arriving infrared rays are sieved by the atmosphere of the Earth holding water vapors. The cloudiness of the atmosphere, especially, is in charge of keeping the hotness of the Earth, in spite of the fact that the outside of the Earth is rather clear to the longer wavelengths in the infrared area [35, 37].

In addition to optical radiations from the Sun, solar energy spectrum carries radio and X-rays as well (Figure 6). Hotter bodies release a larger wavelength of spectrum. Intense radio waves have been detected over the Sun's outside at $330 \mathrm{MHz}$ possessing wavelength of about one meter [35]. 


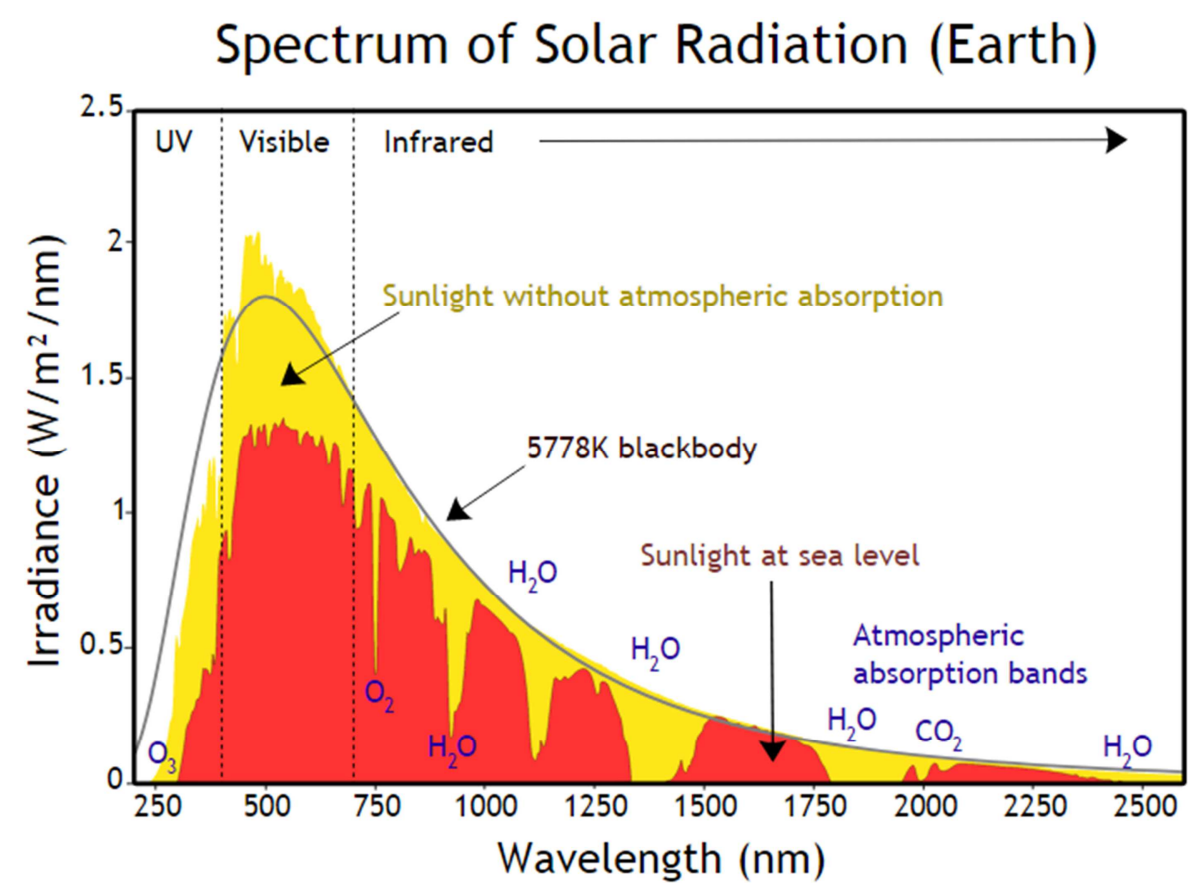

Figure 5. Spectrum of solar radiation (Earth) [36].

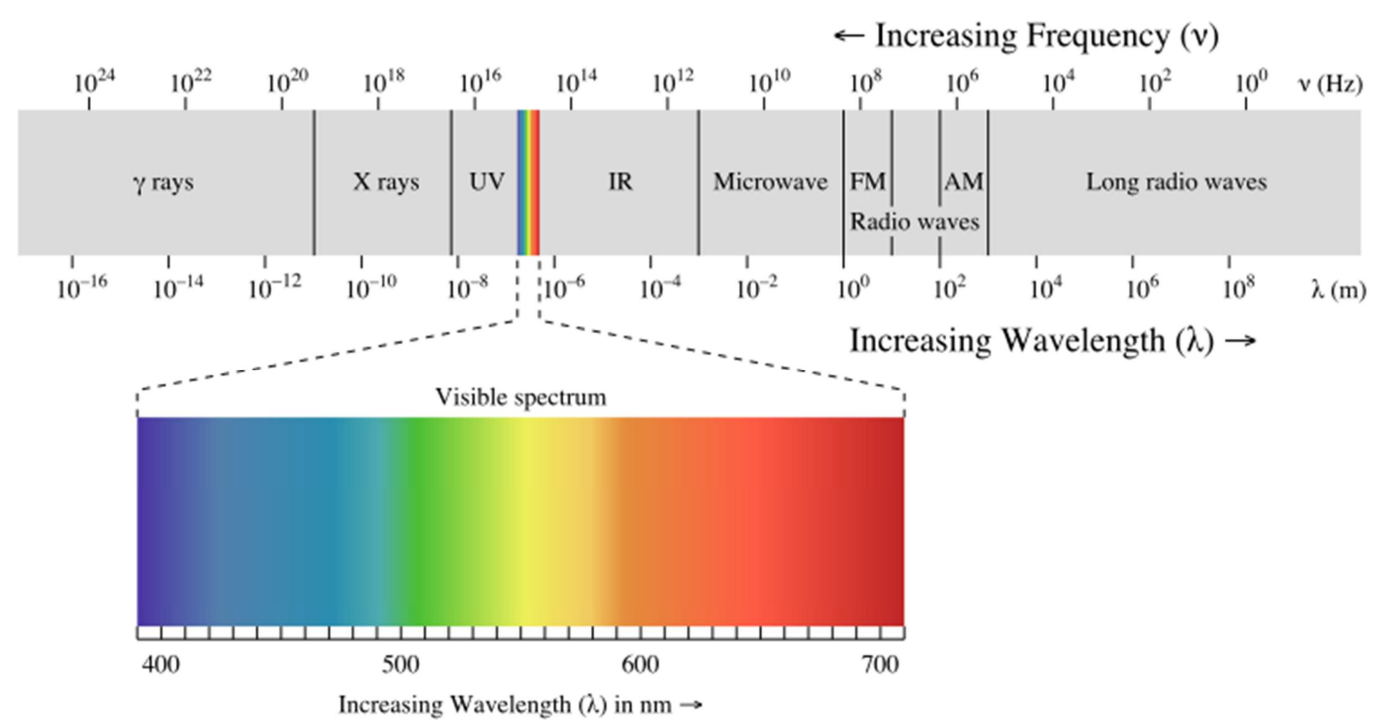

Figure 6. The electromagnetic spectrum [37].

\section{Photo-Induced Toxicity of Environmental Contaminants}

As seen above, solar radiation is a crucial constituent of ecosystem role [38]. Nevertheless, sunlight may as well react with some xenobiotic components in an event called photoinduced, photo-enhanced, photo-activated, or photo-toxicity. This process broadly alludes to a reaction between a chemical and sunlight conducting to an augmented perniciousness. Since most aquatic ecosystems undergo certain quantity of sunlight, co-vulnerability to xenobiotic chemical products and solar radiation is probably to take place in the nature, and photo-induced vulnerability can be a fundamental element affecting aquatic ecosystems.
Nevertheless, photo-induced vulnerability is not probably to be pertinent in all aquatic systems or subjection mechanisms due to change in significant ecological elements as well as physiological adaptations of the species that reside there. Roberts [38] presented an updated review of the state of the science of photo-induced toxicity in aquatic ecosystems.

\section{Conclusions}

The main points drawn from this review are listed as below:

Solar energy is supposed to participate importantly in the global energy supply over the next century, as society transitions away from the use of fossil fuels. To achieve this, scientists must learn how to capture, transfer and store solar 
energy with maximum efficiency at affordable cost.

Nanotechnology is one of the most quickly rising fields of translation al medicine, and its latent effect on photodynamic therapies is very large. The convergence of phototherapy and nanotechnology can give fresh therapeutic modalities (e.g., new nano-photosensitizer formulations) that are painless to bring into practical use everywhere in the body in a targeted method.

Nanotechnology should focus on more using sunlight as a free energy source and an environmentally-friendly agent for its advancing and developing for the humankind best future.

\section{References}

[1] G. E. J. Poinern, The nano world (Ch. 1), A laboratory course in nanoscience and nanotechnology, Taylor \& Francis Group, LLC, Boca Raton, FL, 2015.

[2] M. Salmeron, R. Schlögl, Ambient pressure photoelectron spectroscopy: A new tool for surface science and nanotechnology, Surf. Sci. Rep. 63 (2008) 169-199.

[3] M. Anjum, R. Miandad, M. Waqas, F. Gehany, M. A. Barakat, Remediation of wastewater using various nano-materials, Arabian J. Chem. (2016), http://dx.doi.org/10.1016/j.arabjc.2016.10.004.

[4] A. Hussain, S. M. Arif, M. Aslam, Emerging renewable and sustainable energy technologies: State of the art, Renew. Sustain. Energy Rev. 71 (2017) 12-28.

[5] A. K. Hussein, Applications of nanotechnology to improve the performance of solar collectors - Recent advances and overview, Renew. Sustain. Energy Rev. 62 (2016) 767-792.

[6] A. Quandt, C. Özdoğan, Feynman, biominerals and graphene - Basic aspects of nanoscience, Commun. Nonlinear Sci. Numer.Simulat. 15 (2010) 1575-1582.

[7] C. S. C. Santos, B. Gabriel, M. Blanchy, O. Menes, D. García, M. Blanco, N. Arconada, V. Neto, Industrial applications of nanoparticles - a prospective overview, Mater. Today-Proc. 2 (2015) 456-465.

[8] M. Zäch, C. Hägglund, D. Chakarov, B. Kasemo, Nanoscience and nanotechnology for advanced energy systems, Curr. Opin. Solid St. M. 10 (2006) 132-143.

[9] D. Davchevski, How to increase human energy according to Tesla, http://www.corespirit.com/increase-human-energyaccording-tesla/ (Accessed on 12/01/18).

[10] Arizona State University, Learning from photosynthesis: Synthetic circuits can harvest light energy (13/11/17). https://phys.org/news/2017-11-photosynthesis.html (Accessed on $23 / 01 / 18$ ).

[11] J. Morgan, Heavens above, David Morgan Associates 2014, https://radiantlights.co.uk/press/content/october_2014/mondob.pdf (Accessed on 21/01/18).

[12] C. Arnold, Sunlight could lower your blood pressure (23/01/14), http://blogs.discovermagazine.com/dbrief/2014/01/23/sunlight-may-lower-your-blood-pressure/\#. WmmJ1SZE42x (Accessed on 25/01/18).

[13] J. Troiano, Light can do way more than bend: Part 2, Center for Sustainable Nanotechnology (09/06/15), http://sustainablenano.com/2015/06/09/light-can-do-more-than-bend/ (Accessed on 21/01/18).

[14] L. O. Herrmann, V. K. Valev, C. Tserkezis, J. S. Barnard, S. Kasera, O. A. Scherman, J. Aizpurua, J. J. Baumberg, Threading plasmonic nanoparticle strings with light. Nature Commun. 5 (2014) 4568. doi: 10.1038/ncomms5568.

[15] What is photonics http://www.light2015.org/Home/WhyLightMatters/What-isPhotonics.html (Accessed on 23/01/18).

[16] Á. Blanco, C. López, Photonic crystals: Fundamentals and applications (Ch. 2), Annual Review of Nano Research, Vol. 1, G. Cao, C. J. Brinker (Eds.), World Scientific Publishing Co. Pte. Ltd., New Jersey, 2006.

[17] Nanotech-now, Energetic nanoparticles swing sunlight into electricity (22/02/08). http://www.nanotechnow.com/news.cgi?story_id=28160 (Accessed on 21/01/18).

[18] National geographic, Nanotechnology. https://www.nationalgeographic.org/encyclopedia/nanotechnol ogy/ (Accessed on 24/01/18).

[19] Small sizes that matter: Opportunities and risks of Nanotechnologies, Report in co-operation with the OECD International Futures Programme, OECD, Allianz. http://www.oecd.org/science/nanosafety/44108334.pdf (Accessed on 25/01/18).

[20] W. Adams, A. M. Jaffe, Nanotechnology and our energy challenge (Ch. 2), Environmental nanotechnology, Applications and impacts of nanomaterials, M. R. Wiesner, J.Y. Bottero (Eds.), The McGraw-Hill Companies, New York, 2007.

[21] C. Hägglund, Nanoparticle plasmon influence on the charge carrier generation in solar cells, PhD Thesis, Chalmers University of Technology, Göteborg, Sweden, 2008.

[22] Nanotechnology energizing our future, Nanotechnology DOE Office of Science - Department of Energy. https://science.energy.gov/ /media/bes/images/placemats/nano \%20energy/Nano_LR.pdf (Accessed on 23/01/18).

[23] V. J. Gadgil, F. Morrissey, Applications of focused ion beam in nanotechnology (Vol. 1), 101-110, Encyclopedia of nanoscience and nanotechnology, H. S. Nalwa (Ed.), American Scientific Publishers, New York, 2004.

[24] E. Serrano, G. Rus, J. García-Martínez, Nanotechnology for sustainable energy, Renew. Sustain. Energy Rev. 13 (2009) 2373-2384.

[25] J. L. H. Chau, A. Y. L. Leung, M. B. Shing, K. L. Yeung, C. M. Chan, Hydrogen and proton transport properties of nanoporous zeolite micromembranes (Ch. 27), Nano science and technology: Novel structures and phenomena, Z. Tang, P. Sheng (Eds.), Z. Tang, P. Sheng/CRC Press LLC, New York, 2003 .

[26] M. H. Nayfeh, Optics in nanotechnology (Ch. 10), M. AlAmri, M. El-Gomati, M. Zubairy (Eds.), Optics in our time, Springer, Cham, 2016.

[27] S. Logothetidis, Nanotechnology: Principles and applications (Ch. 1), S. Logothetidis (Ed.), Nanostructured materials and their applications, Springer-Verlag Berlin Heidelberg, 2012. 
[28] L. E. Foster, Nanotechnology: Science, innovation, and opportunity, Prentice Hall, Pearson Education, Inc., New Jersey, 2006.

[29] P. Murphy, D. Munshi, P. A. Kurian, A. Lakhtakia, R. V. Bartlett, Nanotechnology, society, and environment (Ch. 5.15), Elsevier B. V., Amsterdam, 2011.

[30] A. Gupta, P. Avci, M. Sadasivam, R. Chandran, N. Parizotto, D. Vecchio, W. C Antunes-Melo, T. Dai, L. Y. Chiang, M. R. Hamblin, Shining light on nanotechnology to help repair and regeneration, Biotechnol Adv. 31 (2013) 607-631.

[31] N. Bloise, P. Minzioni, M. Imbriani, Livia Visai, Can nanotechnology shine a new light on antimicrobial photodynamic therapies? (Ch. 4), Photomedicine - Advances in Clinical Practice, Y. Tanaka (Ed.), In Tech, Rijeka, Croatia, 2017.

[32] X. Qu, P. J. J. Alvarez, Q. Li, Applications of nanotechnology in water and wastewater treatment, Water Res. 47 (2013) 3931-3946.

[33] Y. Zhao, X. Zhang, Nanobiotechnology: An engineer's foray into biology, Advances in computers, Vol. 71, Elsevier Inc., Amsterdam, 2007.
[34] $20^{\text {th }}$ Century. https://www.iinano.org/20th-century (Accessed on $24 / 01 / 18)$.

[35] H. Rashid, Solar energy (27/05/09), https://hamza1886.blogspot.com/2009/05/solar-energy-natureand-composition.html (Accessed on 31/01/18).

[36] Wikipedia, Sunlight (25/01/18), https://en.wikipedia.org/wiki/Sunlight (Accessed on $31 / 01 / 18)$.

[37] Khanacademy, Light: Electromagnetic waves, the electromagnetic spectrum and photons, https://www.khanacademy.org/science/physics/lightwaves/introduction-to-light-waves/a/light-and-theelectromagnetic-spectrum (Accessed on 31/01/18).

[38] A. P. Roberts, M. M. Alloy, J. T. Oris, Review of the photoinduced toxicity of environmental contaminants, Comp. Biochem. Phys. C 191 (2017) 160-167. 